\title{
Isokinetic evaluation of the trunk muscle strength in housewives with fibromyalgia: a cross-sectional study
}

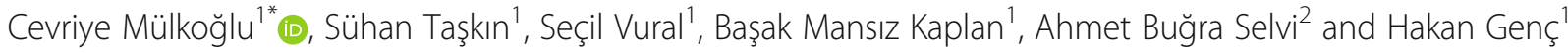

\begin{abstract}
Background: It is known that physical activity and muscular performance are reduced in fibromyalgia (FM) syndrome. This study aims to compare the performance of trunk muscles in women with FM and healthy controls and evaluate the correlation between trunk muscle strength and FM severity.

Methods: Forty-six patients with FM and 42 age- and body mass index-matched healthy housewives without FM were included in the FM and control groups, respectively. The Fibromyalgia Impact Questionnaire (FIQ) was used for the assessment of FM severity. The pain intensity was evaluated using the visual analogical scale (VAS). An isokinetic dynamometer was used to measure the isokinetic trunk muscle strength. The peak torque (PT) values were recorded. The psychological status of the patients was evaluated using the Beck Depression Inventory.
\end{abstract}

Results: There was no statistically significant difference in terms of age, BMI, and BDI scores in two groups ( $p>0.05$, for all). The isokinetic trunk extensor PT values were significantly lower in the FM group ( $p=0.002$ for $60^{\circ} / \mathrm{s}$, and $p<$ 0.001 for $90 \%$ and $120 \%$ s) than control group. There was a statistically significant negative correlation between FIQ score and isokinetic extensor muscle parameters.

Conclusion: The results indicate that trunk extensor muscles were significantly weaker in FM patients. Trunk extensor muscle strength decreased as FM severity increased in FM patients.

Keywords: Fibromyalgia, Muscle, Trunk, Isokinetic

\section{Background}

Fibromyalgia (FM) syndrome is a disorder affecting 2 to $8 \%$ of the general population, characterized by widespread pain, often accompanied by fatigue, memory problems, and sleep architecture disturbances [1]. A published population survey found the prevalence of FM as $6.4 \%$ in Minnesota, USA [2]. In Turkey, the prevalence of FM was determined $3.6 \%$ in women aged 20-64 [3]. The prevalence rises steadily with age, mostly affecting females aged 20 to 65 years [4]. FM prevalence was reported $31 \%$ among 65-80 years-old elderly adults, in another study from Turkey [5].

\footnotetext{
* Correspondence: drckaraca@hotmail.com

'Department of Physical Medicine and Rehabilitation, Health Sciences

University, Ankara Training and Research Hospital, 06230 Ankara, Turkey

Full list of author information is available at the end of the article
}

Although the etiology of FM remains unclear, many factors, including the dysfunction of the central and peripheral nervous system, immune and hormonal system, as well as psychological factors can contribute to FM. Abnormal central sensitization, reduced blood flow to muscles during exercise, increased muscle hypertonicity, localized muscle hypoxia, deposition of mucopolysaccharides within muscles, pathological alterations in the sympathetic system and glycolysis, and decreased ATP and phosphocreatine have been found to be related to FM [6-9].

It is considered that physical capacity, which includes aerobic capacity, muscle strength, flexibility and balance, is impaired in FM patients. Muscle strength is necessary for performing daily activities, such as walking stairs, lifting and carrying heavy objects, and rising from a chair. Prolonged muscle tension and ischemia can cause painful

(c) The Author(s). 2020 Open Access This article is licensed under a Creative Commons Attribution 4.0 International License, which permits use, sharing, adaptation, distribution and reproduction in any medium or format, as long as you give appropriate credit to the original author(s) and the source, provide a link to the Creative Commons licence, and indicate if changes were made. The images or other third party material in this article are included in the article's Creative Commons licence, unless indicated otherwise in a credit line to the material. If material is not included in the article's Creative Commons licence and your intended use is not permitted by statutory regulation or exceeds the permitted use, you will need to obtain permission directly from the copyright holder. To view a copy of this licence, visit http://creativecommons.org/licenses/by/4.0/. 
symptoms in FM, which, in turn, leads to decreased muscle performance and physical capacity. Maximal isometric and isokinetic muscle performance of the upper and lower extremities has been evaluated in many studies [9-19]. Lower extremity muscles are the most evaluated parts of the body in patients with FM. The isokinetic muscle strength of the hip, ankles, and especially knees has been examined in various studies, and the weakening of muscle performance has been reported to range from 26 to $63 \%$ in FM patients $[9,10,13,17,18]$. Maquet et al. compared 16 women with FM to 85 healthy controls and found that knee-extension strength was reduced by $35 \%$ on average in women with FM [13]. Henriksen et al. evaluated 840 women with FM and 122 healthy controls and indicated that isokinetic knee extension strength was decreased by $15-25 \%$ in women with FM [17]. However, there are only a limited number of studies concerning the muscle strength of upper extremities in patients with FM [14-16]. In all these studies, FM patients were reported to have impaired muscle performance of upper extremities compared to healthy controls. Although back pain is one of the most common complaints among FM patients, trunk muscle performance was only investigated in few studies in the literature [12, 20, 21]. In a study, Valkeinen et al. evaluated 23 postmenopausal women and 11 healthy women. They compared isometric upper, lower extremity and trunk muscle strengths and found that women with FM had significantly lower isometric force in bilateral leg extensors, unilateral knee extensors and flexors than healthy women, but no differences were observed in the performance of the trunk and upper extremities [12]. Ghroubi et al. evaluated 21 FM patients and 25 healthy controls. They found that the isokinetic muscle strengths of knee and trunk were decreased in the FM group. The difference between the groups was significant. Isokinetic trunk muscle impairment was predominant in the extensor muscles and decreased by $70 \%$ in the FM group [20]. In another study, Okumus et al. compared 44 osteoporotic patients with FM and 46 osteoporotic women who were physically inactive in terms of abdominal and lumbar muscle strengths. They observed that osteoporotic patients with FM had impaired abdominal and lumbar muscles compared to the control group [21]. Trunk muscle strength is actually extremely important for such patients to maintain daily living activities requiring an erect posture.

The aim of this study was to compare the strength of trunk muscles in housewives with FM and healthy controls and evaluate the correlation between trunk muscle strength and FM severity.

\section{Methods}

Participants: A total of 88 housewives were included in this study between January 2019 and August 2019. This case-control, cross-sectional, single-center study comprised, 46 housewives with FM who submitted to our outpatient clinic with diagnosis of FM according to the 2016 revised FM diagnostic criteria [22] were enrolled in the FM group, and 42 age- and body mass index (BMI)-matched housewives, without FM. The inclusion criteria for the study were being a housewife and higher 18 years old. Patients who had cardiologic, neurological, inflammatory, infectious, psychological diseases, arthritis, severe osteoarthritis, malignancy, lumbar radicular symptoms, inflammatory back pain, those with a history of cervical, thoracic, lumbar spine or abdominal operations, and those using drugs that could affect muscle functions, such as statins and steroids were excluded from the study. In addition, the patients who had history of regular exercise for back and/or aerobic exercise were not included in the study. It is assumed that moderate to heavy-intensity activity at least 3 days in a week for $30 \mathrm{~min}$ and 3 months, as regular exercise habit. This study was approved by the local ethics committee of our institution and performed in accordance with the ethical standards specified in the 1964 Declaration of Helsinki and its later amendments. The patients were informed about the study and written consent was obtained from all participants.

The participants' age, weight and height were noted. The BMI $\left(\mathrm{kg} / \mathrm{m}^{2}\right)$ of the patients was calculated. Disease duration of the patients with FM was noted. Educational status of the subjects was recorded. The participants were also queried about their medications, which affect pain such as nonsteroidal anti-inflammatory drugs (NSAIDs), paracetamol, antidepressants, anticonvulsants and opioids. The detailed examination of the musculoskeletal and neurological system of the patients was performed by the same physiatrist. The visual analogical scale (VAS) was used to evaluate the current pain severity of the patients with FM, based on a chart numbered from 0 to 10 , in whicha score of 0 score indicated no pain while a score of 10 score represented pain of highest severity.

The Turkish version of the Fibromyalgia Impact Questionnaire (FIQ) was used for the assessment of physical functions and severity of FM [23]. FIQ consists of 10 subscales including physical impairment, overall well-being, work days missed, work difficulty, pain, fatigue, morning tiredness, stiffness, anxiety, depression, and daily work and activities of the patients. The first sub-scale contains 11 questions related to physical performance, each rated on a four-point Likert-type scale. The last seven sub-items are scored using VAS with 1-cm increments. The total score ranges from 0 to 100 , with higher scores showing the greater impact of FM on the patient.

The psychological status of the subjects was assessed using the Beck Depression Inventory (BDI) consisting of 21 items about how the subjects felt during the past 1 
week [24]. All of the questions are scored between 0 and 3 , with the total score ranging from 0 to 63 . Scores of 0-9 show minimal depression, 10-16 show mild depression, 17-29 indicate moderate depression, and 30-63 show severe depression.

Isokinetic measurements: The trunk muscle strength was evaluated at the angular velocities of $60^{\circ}, 90^{\circ}$ and $120 \%$ sy a calibrated isokinetic dynamometer (Biodex System 4 Pro; Biodex Corporation, Shirley, NY, U.S.A.). It is known that lower speeds usually would be used to determine the highest torque and fast and/or intermediate speeds focus on greater power and fatigue index. The participants were placed on the dual-position back extension-flexion attachment of the dynamometer with the trunk upright, hips and knees flexed at $90^{\circ}$, and thighs parallel to the floor (Fig. 1). The patients were stabilized with upper trunk, thigh and pelvis straps. The goniometer axis of rotation was aligned with the imaginary line connecting the anterior superior iliac spines [25]. This was considered the anatomic reference position. At this reference position, $30^{\circ}\left(-30^{\circ}\right)$ of trunk flexion and $20^{\circ}\left(+20^{\circ}\right)$ of trunk extension were allowed. The range of trunk motion was $50^{\circ}$. The following isokinetic test protocol was applied: Before muscle strength testing, warm-up tests were performed for all participants. The patients underwent three sets of submaximal warm-up trials before each test. This warm-up trials helped patients become familiar with the equipment and test execution. The main measurements were conducted after the warm-up tests. Five repetitions of flexion/extension cycles at each angular velocities and one-minute rest period between the sets were undertaken. In addition, the patients were encouraged to use maximum effort from the beginning of the first set to the end of the test. The participants were motivated with verbal commands and visual feedbacks on the computer screen during the tests to apply maximum effort. The overall testing duration was approximately $15 \mathrm{~min}$. The isokinetic measurements were performed by the same researcher. The peak torques (PT) values of the trunk flexor and extensor muscles were recorded.

Sample size calculation: G*Power sample size calculation program [26] was used to determine the sample size. The power analysis revealed that this study had $95 \%$ power using type I error $(\alpha)=0.05$, effect size $=0.8$, and a two-sided $t$ test.

\section{Statistical analysis}

Statistical analysis was performed using SPSS software version 23.0 (SPSS version 23.0, IBM, Armonk, NY, USA). The normality of distribution was assessed using visual and statistical methods. Normally distributed data were presented as mean and standard deviation (SD) and for the data without normal distribution, median

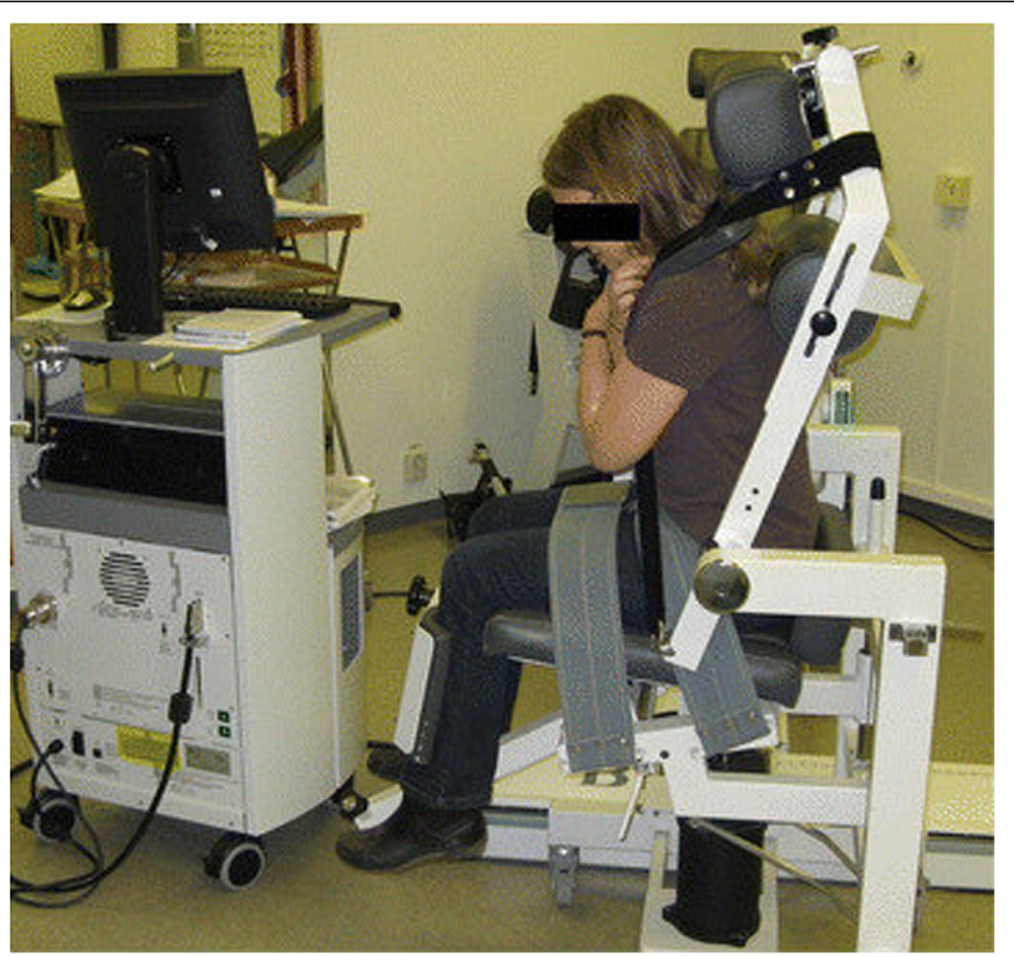

Fig. 1 The position of the participants on the back extension-flexion attachment of the isokinetic dynamometer with the trunk upright, hips and knees flexed at $90^{\circ}$, and thighs parallel to the floor 
and interquartile range (IQR) values were used. For the comparison of the groups, the independent samples t-test (normal distribution) was employed for the quantitative data. The degrees of association between FIQ score (nonnormal distribution) and flexor/extensor muscle PT values were evaluated by the Spearman's correlation analysis. The correlation between the parameters with normal distribution was assessed by the Pearson correlation analysis. Statistical significance was accepted as $p<0.05$.

\section{Results}

The two groups were well-matched in terms of age and BMI ( $p=0.72$ and $p=0.64$, respectively). Educational status and BDI scores were similar in the FM group and the control group, and no statistically significant differences were found between the groups $(p>0.05$, for both). The median FM duration was 3 years (1-9) and FIQ score was $46.6(18.1-60.0)$ in the FM group. Sixtythree percent of the women with FM reported the use of NSAIDs or paracetamol, 26\% reported use of antidepressants and $11 \%$ reported use of anticonvulsants. The demographic and clinical characteristics of the participants are given in Table 1.

All of the isokinetic parameters were lower in the FM group than in the control group. At all three angular velocities, the FM group showed significantly lower extensor PT values than the control group $\left(p=0.002\right.$ for $60^{\circ} \%$ $\mathrm{s}$, and $p<0.001$, both of $90^{\circ} / \mathrm{s}$ and $120^{\circ} / \mathrm{s}$ ). The flexor PT values were also lower in the FM group, but with no statistically significance compared to the control group $(p>0.05)$. The results of the isokinetic measurements of the two groups are given in Table 2.

We found a statistically significant negative correlation between the FIQ score and trunk muscle strengths, except for the $60^{\circ}$ /s flexor PT in FM group. The results of the correlation analysis between FIQ score and isokinetic trunk muscle parameters are given in Table 3.

\section{Discussion}

In this study, we evaluated whether FM patients had decreased trunk muscle performance than those without FM. We found that the strength of extensor trunk muscles was significantly lower in FM patients than in the control group. There are a few studies in the literature investigating trunk muscle dysfunction in FM patients. Ghroubi et al. compared 21 patients with FM and 25 healthy controls in terms of the strength and endurance of the knee and trunk muscles. The strength of trunk muscles was evaluated by using an isokinetic dynamometer at $60 \%$ and $150 \%$ s angular velocities. It was found that the strength and endurance of these muscles were significantly lower in patients with FM than healthy controls. The authors reported that mean decrease was $34.5 \%$ for the trunk flexors and $70 \%$ for the trunk extensors. In the current study, we evaluated trunk muscles with isokinetic dynamometer at three different angular velocities and did not assess the endurance. Although a significant relationship was found between the FIQ score

Table 1 Demographic and clinical characteristics of the participants

\begin{tabular}{|c|c|c|c|}
\hline Variables & $\begin{array}{l}\text { FM group } \\
\mathrm{n}: 46\end{array}$ & $\begin{array}{l}\text { Control group } \\
\mathrm{n}: 42\end{array}$ & $p$ value \\
\hline Age (years) (mean $\pm \mathrm{SD}$ ) & $43.2 \pm 7.4$ & $42.8 \pm 7.1$ & 0.72 \\
\hline BMI $\left(\mathrm{kg} / \mathrm{m}^{2}\right)($ mean $\pm \mathrm{SD})$ & $26.4 \pm 3.8$ & $25.9 \pm 3.6$ & 0.64 \\
\hline Disease duration (years) (min.-max.) & $3(1-9)$ & - & \\
\hline \multicolumn{4}{|l|}{ Educational status } \\
\hline Primary school & 24 & 23 & \\
\hline Middle school & 12 & 10 & 0.83 \\
\hline High school & 8 & 7 & \\
\hline College & 2 & 2 & \\
\hline \multicolumn{4}{|l|}{ Pharmacological treatment } \\
\hline NSAID, paracetamol & $29(63 \%)$ & & \\
\hline Opioids & 0 & - & \\
\hline Antidepressants & $12(26 \%)$ & & \\
\hline Anticonvulsants & $5(11 \%)$ & & \\
\hline VAS score (mean $\pm S D$ ) & $6.0 \pm 1.5$ & - & \\
\hline $\mathrm{BDI}$ score (mean $\pm \mathrm{SD})$ & $18.2 \pm 8.4$ & $17.7 \pm 9.0$ & 0.48 \\
\hline FIQ score (min.-max.) & $46.6(18.1-60.0)$ & - & \\
\hline
\end{tabular}

Bold $p$ values show significance. Statistical significance was set at $p<0.05$

$n$ Number, SD Standart deviation, IQR Interquartile range, FM Fibromyalgia, BMI Body Mass Index, NSAID Non-steroidal anti-inflammatory drug, VAS Visual Analog Scale, $B D I$ Beck Depression Inventory, FIQ Fibromyalgia Impact Questionare 
Table 2 The results of isokinetic measurements of the groups

\begin{tabular}{cccc}
\hline & FM Group & Control Group & $\boldsymbol{P}$ value \\
\hline Extensor PT (N-M) & & & \\
$60 \%$ s Ext. PT & $119.3 \pm 45.9$ & $152.9 \pm 39.4$ & $\mathbf{0 . 0 0 2}$ \\
$90 \%$ sxt. PT & $96.5 \pm 51.9$ & $162.6 \pm 49.0$ & $<\mathbf{0 . 0 0 1}$ \\
$120 \%$ sxt. PT & $66.6 \pm 53.0$ & $140.0 \pm 55.2$ & $<\mathbf{0 . 0 0 1}$ \\
Flexor PT (N-M) & & & \\
$60 \%$ s Flex. PT & $78.4 \pm 26.8$ & $82.3 \pm 21.3$ & 0.50 \\
$90 \%$ Flex. PT & $66.0 \pm 25.1$ & $76.1 \pm 21.6$ & 0.08 \\
$120 \%$ s Flex. PT & $52.5 \pm 27.0$ & $60.3 \pm 21.7$ & 0.19 \\
\hline
\end{tabular}

Bold $p$ values show significance. Statistical significance was set at $p<0.05$ FM Fibromyalgia, $P T$ Peak Torque, $N-M$ Newton meters

and isokinetic parameters in the present study, the authors did not determine any correlation between the isokinetic parameters and FIQ score. Similar to our study, the authors found that muscle impairment was predominant in the extensor trunk muscles [20]. This implies that the extensor muscles are more affected than flexors in patients with FM. In another study, Valkeinen et al. compared aerobic performance, isometric upper extremity, lower extremity and trunk muscle strength between 23 postmenopausal women with FM and 11 healthy women. They mentioned that postmenopausal women with FM had significantly lower isometric force in bilateral leg extensors, unilateral knee extensors and flexors than healthy women, but no differences were observed in the strength of trunk and upper extremities [12]. Although we evaluated trunk muscles with isokinetic dynamometer, they used the isometric method. In contrast to our study, the authors did not find any difference in strength of trunk muscles between the groups. Okumus et al. assessed the strength of abdominal and

Table 3 The results of correlation analysis between FIQ score and isokinetic trunk muscle parameters

\begin{tabular}{|c|c|}
\hline & FIQ score \\
\hline \multicolumn{2}{|l|}{ Extensor PT (N-M) } \\
\hline $60^{\circ} / \mathrm{s}$ Ext. PT & $\begin{array}{l}r:-0.36 \\
\boldsymbol{p}<\mathbf{0 . 0 5}\end{array}$ \\
\hline $90^{\circ} / \mathrm{s}$ Ext. PT & $\begin{array}{l}r:-0.46 \\
p<0.001\end{array}$ \\
\hline $120^{\circ} / \mathrm{s}$ Ext. PT & $\begin{array}{l}r:-0.45 \\
\boldsymbol{p}<\mathbf{0 . 0 0 1}\end{array}$ \\
\hline \multicolumn{2}{|l|}{ Flexor PT (N-M) } \\
\hline $60 \%$ s Flex. PT & $\begin{array}{l}r:-0.20 \\
p: 0.09\end{array}$ \\
\hline $90^{\circ}$ s Flex. PT & $\begin{array}{l}r:-0.28 \\
\boldsymbol{p}<\mathbf{0 . 0 5}\end{array}$ \\
\hline $120^{\circ} / \mathrm{s}$ Flex. PT & $\begin{array}{l}r:-0.24 \\
p<0.05\end{array}$ \\
\hline
\end{tabular}

Bold $p$ values show significance. Statistical significance was set at $p<0.05$ PT Peak Torque, $N-M$ Newton meters, FIQ Fibromyalgia Impact Questionnaire lumbar muscles in 44 osteoporotic patients with FM and 46 osteoporotic women without FM who were physically inactive. They observed that osteoporotic patients with and without FM had impaired abdominal and lumbar muscles. The strength of lumbar muscles was found significantly lower in FM patients as compared to the controls [21]. In the current study, the control group consisted of physically active healthy individuals, and the patients with FM had weaker trunk muscles than healthy controls. This finding can be explained with the fact that FM patients are relatively de-conditioned and they have abnormal perceived pain as compared with non-FM subjects.

Sempere-Rubio et al. found that the FM population presented with a different trunk posture and an inability to maintain an erect position. In that study, a specific posture with significantly larger thoracic kyphosis, baseline shoulder protraction, and lower craniovertebral angle and maximum protraction was noted in the FM group compared to the control group [27]. In the current study, we found that the extensor strength of trunk muscles was significantly lower in patients with FM. FM patients may not adequately demonstrate muscle performance due to the impaired posture. In addition, weaker extensor muscles may result in not being able to maintain an erect posture. The deterioration of the erect posture may cause increased muscular pain, and thus a vicious circle starts between impaired posture and pain. Furthermore, patients may have difficulty in daily activities that require an upright posture, such as standing, travelling, lifting, dressing, and walking. This is supported by the objective data obtained from our study, revealing that the FM group had significantly weaker strength in the trunk extensor muscle compared to the healthy controls.

Larsson et al. described the possible reasons for decreased muscle strength in FM, including pathologic changes in muscle fibers, impaired blood circulation, and disturbances in the regulation of growth and energy metabolism. They suggested that other possible explanations included altered neuromuscular control mechanisms caused by pain or decreased levels of physical activity in women with FM. Women with FM spend more time engaging in sedentary activities and less time engaging in high-intensity activities [11]. Jimenez et al. reported that FM patients had longer sedentary times and engaged in less physical activity [28]. Decreased physical activity and longer sedentary times may have a negative effect on trunk muscle performance in FM patients. According to our results, it was found that trunk muscles strengths of the patients were weak, even at higher speeds (Table 2). This finding could be related to muscle resistance parameters, and may also be related to fatigue. We have also determined a significant 
negative correlation between FM severity and isokinetic muscle parameters, so the patients with more severe FM may have more impaired trunk muscle performance. Henriksen et al. did not find any clinically significant correlation between FIQ score and isokinetic knee muscle strength [17]. We found that trunk muscle strengths especially extensors were negatively affected with FM severity. Increased FM severity may imply decreased extensor trunk muscle strength. We believe that strengthening exercises for extensor trunk muscles can reduce the severity of FM in these patients. However, the correlations obtained from the current study were low, and therefore the clinical relevance of the associations may be minor. Thus, the results should be interpreted with caution. To clarify our results, further prospective studies are needed to evaluate the effects of FM on trunk muscle performance.

In FM patients, pain worsens the physical activity because these patients use their muscles for a shorter time due to the pain and undertake less physical activity during their daily lives. Although the relationship between pain and physical function has not yet been clearly understood, pain is known to contribute to reduced functional capacity in FM. Soriano-Maldonado et al. reported that higher muscle strength was consistently associated with lower levels of pain and lower FM severity in women with FM $[29,30]$. Pain in patients with FM has been related with increased disease severity, reduced function, and symptoms of FM. Thus, pain is a significant symptom that may contribute to not participate in functional activity [31-33]. In one study, it was indicated that women with FM showed reduced functional activity and lower limb muscle strength, mostly due to pain [33].

Sener et al. found that handgrip strength and back-leg strength were significantly decreased in FM patients than healthy controls and also showed a moderately negative correlation between muscle strength and BDI scores in FM patients [19]. Since baseline depression is common in FM patients, these findings support impaired muscle strength in this patient group. In the current study, we found no significantly difference in terms of BDI score in two groups. In this case, it is not possible to associate the decreased trunk muscle strength with depression in FM group.

Hooten et al. reported that strength and aerobic exercise had equivalent effects on reducing pain severity among patients with FM [34]. We also suggest that exercise treatments that include strength exercises may have beneficial effects on patients with FM. New strategies for incorporating strengthening exercises for trunk muscles especially for extensors into the life styles of FM patients should be supported by healthcare professionals.

There are some limitations to this study. We included only housewives and conducted this study with women who had FM. Another limitation of this study is that we have not evaluated fatigue which is an important symptom in FM patients. Further prospective trials are needed to investigate trunk muscle performance also in men with FM, as well as individuals from various occupation groups and larger populations.

\section{Conclusion}

The results of this study revealed that the strength of extensor trunk muscles decreased in FM patients than those without FM. In addition, we determined that as the severity of FM increased, the trunk extensor muscle performance decreased. There is a clear need for further investigations about the mechanism of impaired trunk muscles and the effects of strengthening exercises engaging extensor trunk muscles in FM patients.

\section{Abbreviations}

FM: Fibromyalgia; FIQ: Fibromyalgia impact questionnaire; VAS: Visual analog scale; BMI: Body mass index; BDI: Beck depression inventory; PT: Peak torque

\section{Acknowledgements}

Not applicable.

\section{Authors' contributions}

CM: Designed of the study and drafted the manuscript; CM and SV: Literature search; CM, ST and ABS: Collecting the data, performing isokinetic tests; CM and BMK: Statistical analysis; CM and HG: Supervising and editing the manuscript. All authors have read and approved the final version of the article.

Funding

No funding was obtained for this study.

\section{Availability of data and materials}

The data sets generated and/or analysed during the current study are not publicly available due to the patients' privacy but are available from the corresponding author on reasonable request.

Ethics approval and consent to participate

This study was approved by the ethics committee of Ankara Training and Research Hospital by number of 133/19.12.2019.

\section{Consent for publication}

Written informed consent was obtained from the participants for publication of this study and any accompanying images

\section{Competing interests}

The authors declare that no conflict of interest.

\section{Author details}

${ }^{1}$ Department of Physical Medicine and Rehabilitation, Health Sciences University, Ankara Training and Research Hospital, 06230 Ankara, Turkey. ${ }^{2}$ Department of Physiotherapy and Rehabilitation, Health Sciences University, Ankara Training and Research Hospital, 06230 Ankara, Turkey.

Received: 26 April 2020 Accepted: 6 August 2020

Published online: 14 August 2020

\section{References}

1. Clauw DJ. Fibromyalgia: a clinical review. JAMA. 2014;311(15):1547-55. https://doi.org/10.1001/jama.2014.3266.

2. Vincent A, Lahr BD, Wolfe F, et al. Prevalence of fibromyalgia: a populationbased study in Olmsted County, Minnesota, utilizing the Rochester epidemiology project. Arthritis Care Res. 2013;65:786-92. 
3. Topbas M, Cakirbay H, Gulec $\mathrm{H}$, et al. The prevalence of fibromyalgia in women aged 20-64 in Turkey. Scand J Rheumatol. 2005;34(2):140-4.

4. Rahman A, Underwood M, Carnes D. Fibromyalgia. BMJ. 2014;348:g1224. https://doi.org/10.1136/bmj.g1224.

5. Garip Y, Öztaş D, Güler T. Prevalence of fibromyalgia in Turkish geriatric population and its impact on quality of life. Agri. 2016;28(4):165-70.

6. Abeles AM, PillingerMH SBM, et al. Narrative review: the pathophysiology of fibromyalgia. Ann. Intern. Med. 2007;146:726-34.

7. Vierck CJ Jr. Mechanisms underlying development of spatially distributed chronic pain (fibromyalgia). Pain. 2006;124:242-63.

8. Yunus MB. Fibromyalgia and overlapping disorders: the unifying concept of central sensitivity syndromes. Semin Arthritis Rheum. 2007;36:339-56.

9. Yetişgin $A$, Tiftik $T$, Kara $M$, et al. Isokinetic muscle performance of the hip and ankle muscles in women with fibromyalgia. Int J Rheum Dis. 2016;19(6): 551-6.

10. Hooten WM, Rosenberg CJ, Eldrige JS, et al. Knee extensor strength is associated with pressure pain thresholds in adults with fibromyalgia. PLoSOne. 2013;8(4):e59930. https://doi.org/10.1371/journal.pone.0059930.

11. Larsson A, Palstam A, Bjersing J, et al. Controlled, cross-sectional, multicenter study of physical capacity and associated factors in women with fibromyalgia. BMC Musculoskelet Disord. 2018;19(1):121. https://doi.org/10. 1186/s12891-018-2047-1.

12. Valkeinen $\mathrm{H}$, Häkkinen $\mathrm{A}$, Alen $\mathrm{M}$, et al. Physical fitness in postmenopausal women with fibromyalgia. Int J Sports Med. 2008;29(5):408-13.

13. Maquet $\mathrm{D}$, Croisier $\mathrm{JL}$, Renard $\mathrm{C}$, et al. Muscle performance in patients with fibromyalgia. Joint Bone Spine. 2002;69(3):293-9.

14. Güler H, Yıldızgören MT, Üstün N, et al. Isokinetic assessment of the wrist muscles in females with fibromyalgia. Arch of Rheumatol. 2016;31(3):215-20.

15. Nordenskiöld UM, Grimby G. Grip force in patients with rheumatoid arthritis and fibromyalgia and in healthy subjects. A study with the Grippit instrument. Scand J Rheumatol. 1993;22:14-9.

16. Mengshoel AM, Førre O, Komnaes HB. Muscle strength and aerobic capacity in primary fibromyalgia. Clin Exp Rheumatol. 1990;8:475-9.

17. Henriksen M, Lund $\mathrm{H}$, Christensen $\mathrm{R}$, et al. Relationships between the fibromyalgia impact questionnaire, tender point count, and muscle strength in female patients with fibromyalgia: a cohort study. Arthritis Rheum. 2009; 61(6):732-9

18. Borman P, Celiker R, Hasçelik Z. Muscle performance in fibromyalgia syndrome. Rheumatol Int. 1999;19(1-2):27-30.

19. Sener U, Ucok K, Ulasli AM, et al. Evaluation of health-related physical fitness parameters and association analysis with depression, anxiety, and quality of life in patients with fibromyalgia. Int J Rheum Dis. 2016;19(8):763-72. https:// doi.org/10.1111/1756-185X.12237.

20. Ghroubi S, Jribi S, Akrout R, et al. Relationships between the fibromyalgia impact questionnaire, pain severity, psychological profile and muscle strength in female patients with fibromyalgia. Ann Phys Rehabil Med. 2015; 58(1):e39. https://doi.org/10.1016/.j.ehab.2015.07.098.

21. Okumus M, Gokoglu F, Kocaoglu S, et al. Muscle performance in patients with fibromyalgia. Singap Med J. 2006;47:752-6.

22. Wolfe F, Clauw DJ, Fitzcharles MA, et al. 2016 revisions to the 2010/2011 fibromyalgia diagnostic criteria. Semin Arthritis Rheum. 2016;46(3):319-29.

23. Sarmer $S$, Ergin S, Yavuzer $G$. The validity and reliability of the Turkish version of the fibromyalgia impact questionnaire. Rheumatol Int. 2000; 20(1):9-12.

24. Richter P, Werner J, Heerlein A, et al. On the validity of the Beck depression inventory. A review. Psychopathology. 1998;31(3):160-8

25. Grabiner M, Jeziorowski J. Isokinetic trunk extension and flexion strengthendurance relationships. Clin Biomech. 1991;6(2):118-22.

26. Faul $F$, Erdfelder $E$, Lang $A G$, et al. $G^{*}$ power 3: a flexible statistical power analysis program for the social, behavioral, and biomedical sciences. Behav Res Methods. 2007;39:175-91.

27. Sempere-Rubio N, Aguilar-Rodríguez M, Espí-López GV, et al. Impaired trunk posture in women with fibromyalgia. Spine (PhilaPa 1976). 2018;43(22): 1536-42. https://doi.org/10.1097/BRS.0000000000002681.

28. Jimenez VS, Gallardo ICA, Lopez FE, et al. Differences in sedentary time and physical activity between female patients with fibromyalgia and healthy controls: the al-Ándalus project. Arthritis Rheumatol. 2015;67(11):3047-57.

29. Soriano-Maldonado A, Ruiz JR, Aparicio VA, et al. Association of Physical Fitness with pain in women with fibromyalgia: the al-Ándalus project. Arthritis Care Res (Hoboken). 2015;67(11):1561-70.
30. Soriano-Maldonado A, Henriksen M, Segura-Jiménez V, et al. The association of physical fitness with fibromyalgia severity in women: the al-Ándalus project. Arch Phys Med Rehabil. 2015;96(9):1599-605.

31. Silverman S, Sadosky A, Evans C, et al. Toward characterization and definition of fibromyalgia severity. BMC Musculoskelet Disord. 2010;11:66. https://doi.org/10.1186/1471-2474-11-66.

32. Dailey DL, Frey Law LA, Vance CG, et al. Perceived function and physical performance are associated with pain and fatigue in women with fibromyalgia. Arthritis Res Ther. 2016;18:68. https://doi.org/10.1186/s13075016-0954-9.

33. Góes SM, Leite N, Shay BL, et al. Functional capacity, muscle strength and falls in women with fibromyalgia. Clin Biomech (Bristol, Avon). 2012;27(6): 578-83. https://doi.org/10.1016/j.clinbiomech.2011.12.009.

34. Hooten WM, Qu W, Townsend CO, et al. Effects of strength vs aerobic exercise on pain severity in adults with fibromyalgia: a randomized equivalence trial. Pain. 2012;153:915-23.

\section{Publisher's Note}

Springer Nature remains neutral with regard to jurisdictional claims in published maps and institutional affiliations.
Ready to submit your research? Choose BMC and benefit from:

- fast, convenient online submission

- thorough peer review by experienced researchers in your field

- rapid publication on acceptance

- support for research data, including large and complex data types

- gold Open Access which fosters wider collaboration and increased citations

- maximum visibility for your research: over $100 \mathrm{M}$ website views per year

At $\mathrm{BMC}$, research is always in progress.

Learn more biomedcentral.com/submissions 